(с) И.А. Хрипун*, С.В. Воробьев

Ростовский государственный медицинский университет, Ростов-на-Дону

ОБОСНОВАНИЕ. Сахарный диабет 2 типа (СД2) и гипогонадизм являются взаимоотягощающими состояниями, ассоциированными с развитием и прогрессией кардиоваскулярных заболеваний. Состояние функции эндотелия у мужчин с СД2 на фоне гипогонадизма мало изучено.

ЦЕЛЬ. Оценить влияние гипогонадизма на функцию эндотелия у мужчин с СД2.

МЕТОДЫ. Больным проводили общеклинические исследования, изучение состояния углеводного и липидного обменов, содержания половых гормонов (общего тестостерона (Т), глобулина, связывающего половые гормоны, свободного Т, лютеинизирующего гормона) и маркеров функции эндотелия (оксида азота (NO), эндотелиальной синтазы оксида азота 3 типа (eNOS3), эндотелина, молекул адгезии ICAM-1, VCAM-1, p- и е-селектинов, кадгерина), выполняли ультразвуковые исследования эндотелий-зависимой вазодилатации (ЭЗВД) плечевой артерии (ПА) и сонных артерий с оценкой толщины комплекса интима-медиа (КИМ).

РЕЗУЛЬТАТЫ. В исследование вошли 276 мужчин с СД2 (возраст 54,0 [49; 60] года), которые были разделены на 2 группы: 1 - 124 больных, имеющих гипогонадизм; $2-152$ эугонадных пациента. Нарушение сосудодвигательной функции эндотелия было выявлено у 32,4\% больных 2-й группы и у 55,3\% 1-й группы $\left(x^{2}=6,1 ; p=0,01\right)$, что было ассоциировано со снижением ЭЗВД на $29,8 \%(p<0,001)$ и увеличением времени развития максимальной вазодилатации ПА на 30 с у больных гипогонадизмом ( $<<0,001)$. Толщина КИМ сонных артерий была больше на 10\% в 1-й группе по сравнению со 2-й $(p=0,03)$. Содержание NO в 1-й группе было снижено в 1,6 раза $(p=0,001)$, eNOS3 - в 1,5 раза (p=0,038) по сравнению со 2-й группой. Концентрации молекул адгезии были выше в 1-й группе по сравнению со 2-й:VCAM-1 на $32,5 \%(p<0,001)$, ICAM-1 — на 43,5\% (p<0,001), p-селектина — на 19,3\% (p=0,004), кадгерина — в 6 раз ( $<<0,001)$.

ЗАКЛЮЧЕНИЕ. Гипогонадизм у мужчин с СД2 ассоциирован с развитием дисфункции эндотелия, что проявляется в ослаблении ЭЗВД и замедлении ее развития, а также нарушении секреторной активности эндотелия - снижении синтеза NO и активации экспрессии молекул адгезии, что может являться универсальным патогенетическим механизмом развития сердечно-сосудистых заболеваний при сочетании дефицита Т и СД2.

КЛЮЧЕВЫЕ СЛОВА: гипогонадизм; тестостерон; сахарный диабет; сердечно-сосудистые заболевания; эндотелий; эндотелиальная дисфункция; эндотелий-зависимая вазодилатация; толщина комплекса интима-медиа; оксид азота; молекулы адгезии

\title{
ENDOTHELIAL FUNCTION STATUS IN HYPOGONADAL MEN
}

(C) Irina A. Khripun*, Sergey V. Vorobyev

Rostov State Medical University, Rostov-on-Don, Russia

BACKGROUND: Type 2 diabetes mellitus (T2DM) and hypogonadism are mutually aggravating diseases associated with the development and progression of cardiovascular pathology. The status of endothelial function in men with T2DM and hypogonadism hasn't been studied.

AIMS: To assess the effect of hypogonadism on endothelial function in men with T2DM.

MATERIALS AND METHODS: Patients underwent clinical studies, assessment of carbohydrate and lipid metabolism, the content of sex hormones (total testosterone $(T)$, sex hormones binding globulin, free T, luteinizing hormone) and markers of endothelial function (nitric oxide (NO), endothelial nitric oxide synthase type 3 (eNOS3), endothelin, adhesion molecules ICAM-1, VCAM-1, p- and e-selectins, cadherin), ultrasound examinations of endothelium-dependent vasodilation (EDVD) of the brachial artery (BA) and carotid arteries with an assessment of the thickness of intima-media complex (TIM) were performed.

RESULTS: The study included 276 men with T2DM (age 54.0[49;60] years), who were divided into 2 groups: 1-124 patients with hypogonadism; 2-152 eugonadal patients. Reduction of the endothelial vasomotor function was detected in $32.4 \%$ of patients in the $2^{\text {st }}$ group and in $55.3 \%$ of the $1^{\text {nd }}$ group $\left(x^{2}=6.1 ; p=0.01\right)$, which was associated with a decrease in EDVD by $29.8 \%(p<0.001)$ and an increase in the time of development of maximal BA vasodilation by 30 seconds in patients with hypogonadism $(p<0.001)$. The TIM of the carotid arteries was $10 \%$ more in group 1 compared with group 2 ( $p=0.03)$. The level 
of NO in the $1^{\text {st }}$ group was reduced by 1.6 times $(p=0.001)$, eNOS3-by 1.5 times $(p=0.038)$ compared with the $2^{\text {nd }}$ group. The concentrations of adhesion molecules were higher in group 1 compared to group 2:VCAM-1 by $32.5 \%$ ( $p<0.001)$, ICAM-1 by $43.5 \%(p<0.001)$, $p$-selectin-by $19.3 \%(p=0.004)$, cadherin-6 times $(p<0.001)$.

CONCLUSION: Hypogonadism in men with T2DM is associated with the development of endothelial dysfunction, which manifests in a weakening of the EDVD and a slowdown in its development, as well as disturbances of the secretory activity of endothelium-a decrease in NO synthesis and activation of the adhesion molecules expression, which can be regarded as an universal pathogenetic mechanism of the development of cardiovascular diseases in combination of T deficiency and T2DM.

KEYWORDS: hypogonadism; testosterone; diabetes mellitus; cardiovascular diseases; endothelium; endothelial dysfunction; endothelium dependent vasodilation; the thickness of the intima-media complex; nitric oxide; adhesion molecules

\section{ОБОСНОВАНИЕ}

Широкая распространенность сахарного диабета (СД) в мире, ее неуклонный рост наряду с высокой смертностью данной категории больных от сердечно-сосудистых заболеваний делают изучение этой проблемы неизменно актуальным. Установлено, что кардиоваскулярный риск у больных СД вдвое выше, чем в популяции, что обусловлено влиянием на сосудистое русло глюкозо- и липотоксичности, оксидативного стресса и многих других факторов $[1,2]$. Являясь первым барьером для гипергликемии и гиперлипидемии, эндотелий подвержен их повреждающему влиянию, что приводит к эндотелиальной дисфункции (ЭД) [2, 3]. Важным является тот факт, что появление ЭД происходит за несколько лет до клинических симптомов кардиоваскулярных заболеваний, что при своевременном ее выявлении позволяет предотвратить развитие сосудистых осложнений СД [4-6]. Это диктует необходимость проведения исследований, посвященных изучению ЭД как стартового механизма поражения органов и тканей при СД у пациентов с высоким кардиоваскулярным риском.

В то же время известно, что нарушения углеводного обмена и дефицит тестостерона (Т) у мужчин взаимно отягощают друг друга [7, 8], а смертность от сердечно-сосудистых заболеваний больных СД 2 типа (СД2) в сочетании с гипогонадизмом более чем вдвое выше, чем у эугонадных пациентов [9]. По данным различных исследований, распространенность гипогонадизма у мужчин с СД2 составляет от $30 \%$ до более чем $50 \%[7,10]$. С одной стороны, дефицит Т ухудшает многие метаболические параметры - показатели углеводного и липидного обменов, инсулинорезистентность, функцию жировой ткани, что способствует развитию декомпенсации СД и прогрессии его осложнений $[8,10,11]$. С другой стороны, больные СД2 имеют более низкие уровни Т, чем мужчины без нарушений углеводного обмена [7]. Сочетание этих факторов синергично отягощает течение сердечно-сосудистых заболеваний, а увеличение кардиоваскулярных рисков у мужчин с дефицитом Т вне зависимости от наличия СД позволяет предполагать, что гипогонадизм является независимым фактором риска сердечно-сосудистой смертности [9]. Помимо негативного влияния гипогонадизма на многочисленные факторы кардиоваскулярных рисков, существует и прямое действие Т на сердце и сосуды, осуществляющееся через геномные и негеномные механизмы $[9,12]$. Предполагается, что эндотелий является самостоятельным органом-мишенью для андрогенов. Так, в эндотелиоцитах обнаружена экспрессия рецепторов андрогенов, через взаимодействие с которыми Т реализуются его биологические эффекты [13, 14$]$.
Было показано нарушение функции эндотелия при снижении чувствительности андрогеновых рецепторов вне зависимости от уровня Т [15]. Однако работы о влиянии Т на эндотелий крайне малочисленны, а механизмы этого воздействия остаются неизученными.

\section{ЦЕЛЬ}

Оценить влияние гипогонадизма на функцию эндотелия у мужчин с СД2.

\section{МЕТОДЫ}

\section{Дизайн исследования}

Проведено интервенционное сплошное одномоментное одноцентровое проспективное сравнительное исследование.

\section{Критерии соответствия}

Критерии включения: СД2 длительностью не менее 1 года, мужской пол, возраст 40-65 лет, лечение СД2 пероральными сахароснижающими препаратами, стабильность сопутствующей терапии в течение 3 мес, информированное согласие на участие в исследовании.

Критерии исключения: острые или обострение хронических воспалительных заболеваний, инсулинотерапия СД2, инфаркт миокарда в анамнезе за последние 6 мес, установленный диагноз онкологического заболевания, классические формы гипогонадотропного или гипергонадотропного гипогонадизма, гиперпролактинемический синдром и нарушения функции щитовидной железы.

\section{Условия проведения}

Исследование проводили на базе эндокринологического отделения клиники ФГБОУ ВО «Ростовский государственный медицинский университет» МЗ РФ. В исследование включали как больных, находившихся на стационарном лечении, так и пациентов, обратившихся за амбулаторной помощью.

Продолжительность исследования

Включение пациентов в исследование производили с 2014 по 2018 гг.

\section{Описание медицинского вмешательства}

Проводили сбор жалоб, изучение анамнеза, измерение антропометрических показателей (масса тела, рост, индекс массы тела (ИМТ), окружность талии (ОТ), окружность бедер (ОБ)). У пациентов осуществляли забор венозной крови объемом 10 мл, строго натощак после 12-часового 
голодания. Для проведения биохимических анализов использовали свежую сыворотку крови, иммуноферментные исследования осуществляли из сыворотки, замороженной при температуре $-20^{\circ} \mathrm{C}$. Состояние углеводного и липидного обменов оценивали при помощи следующих показателей: глюкоза и иммунореактивный инсулин (ИРИ) натощак с расчетом индекса инсулинорезистентности НОМА, гликированный гемоглобин $\left(\mathrm{HbA}_{1 c}\right)$ и липидограмма (общий холестерин, уровень триглицеридов, ЛПНП). Также изучали содержание половых гормонов - общего Т, глобулина, связывающего половые гормоны (ГСПГ), расчетного свободного Т, лютеинизирующего гормона (ЛГ) и маркеров функции эндотелия - оксида азота (NO), эндотелиальной синтазы оксида азота 3 типа (eNOS3), эндотелина, молекул адгезии ICAM-1, VCAM-1, р- и е-селектинов, кадгерина. Инструментальное обследование включало ультразвуковое исследование эндотелий-зависимой вазодилатации (ЭЗВД) плечевой артерии (ПА) по методике D. Celermajer (1992) и ультразвуковое исследование сонных артерий с оценкой толщины комплекса интима-медиа (КИМ).

\section{Основной исход исследования}

В качестве основных конечных точек исследования были приняты показатели сосудодвигательной функции эндотелия (ЭЗВД ПА и время развития максимальной вазодилатации ПА) по данным ультразвукового исследования и показатели секреторной функции эндотелия (концентрации NO, eNOS3, эндотелина, ICAM-1, VCAM-1, p- и е-селектинов, кадгерина).

\section{Дополнительные исходы исследования}

Дополнительными конечными точками исследования были показатели углеводного и липидного обменов, показатель КИМ сонных артерий.

\section{Анализ в подгруппах}

На основании проведенного клинического и лабораторного обследования, в зависимости от наличия или отсутствия гипогонадизма пациенты были разделены на две группы.

- В 1-ю группу были включены мужчины с СД2 с впервые установленным диагнозом гипогонадизма.

- Во 2-ю группу включили эугонадных пациентов с СД2.

\section{Методы регистрации исходов}

Оценку показателей гликемии, липидограммы и ферментов печени проводили при помощи анализатора Bayer ADVIA 1650, определение $\mathrm{HbA}_{1 c}$ - Siemens Healthcare Diagnostics DCA 2000+. Иммуноферментный анализ выполняли с использованием анализатора Zenyth 340. Иммуноферментный анализ уровней половых гормонов проводили при помощи лабораторных наборов «Алкор-Био» (Россия), ИРИ - Monobind Inc. (США). Степень выраженности инсулинорезистентности определяли при помощи расчета индекса НОМА по формуле: HOMA-IR = гликемия натощак (ммоль/л) × уровень инсулина (мкЕд/мл) / 22,5.

Маркеры функции эндотелия определяли при помощи лабораторных наборов: ICAM-1, VCAM-1, p- и е-селектинов, кадгерина - «Бендер Медсистемс Гмбх» (Австрия); eNOS3 - BCM Diagnostics (США), эндотелина — «Биомедика Медицин продукте ГмбХ \& Ко КГ» (Австрия). Содержание NO в сыворотке крови определяли расчетным методом путем вычисления разности нитритов и нитратов как продуктов метаболизма NO в соответствии с рекомендациями производителя (R\&D, CШA).

Ультразвуковое исследование артериальной вазореактивности проводили с помощью теста реактивной гиперемии с последующим проведением пробы с сублингвальным приемом нитроглицерина согласно методике D. Celermajer. Изучение ЭЗВД проводили на ПА, для получения изображения и измерения диаметра которой использовали ультразвуковую систему Philips HD 11, оснащенную линейным датчиком с фазированной решеткой (частота 7,0 МГц). ЭЗВД ПА при проведении пробы с реактивной гиперемией рассчитывали по формуле:

$$
\text { ЭЗВД ПА }=\frac{\text { диаметр ПА - исходный диаметр ПА }}{\text { исходный диаметр ПА }} \times 100 \% .
$$

Помимо общепринятой оценки прироста диаметра ПА, характеризующего пространственные характеристики ЭЗВД, в ходе теста с реактивной гиперемией производили измерение времени развития максимальной вазодилатации ПА, отражающего временные характеристики ЭЗВД. В ходе исследования диаметр ПА измеряли исходно, на 1-й минуте - каждые 15 с, затем каждые 30 с вплоть до 5 мин после декомпрессии. При проведении статистического анализа использовали показатель времени развития максимальной вазодилатации ПА, то есть значение секунды, на которой произошло наибольшее расширение ПА после декомпрессии манжеты. Помимо этого, всем пациентам проводили ультразвуковое исследование толщины КИМ задней стенки общих сонных артерий согласно стандартизованной методике P. Pignoli.

\section{Этическая экспертиза}

Bce пациенты до начала исследования подписали форму информированного согласия, одобренную Локальным этическим комитетом Ростовского государственного медицинского университета (протокол №13/14 от 11.09.2014).

\section{Статистический анализ}

Принципы расчета размера выборки. Размер выборки предварительно не рассчитывался.

Методы статистического анализа данных. Статистический анализ данных проводили при помощи пакета прикладных программ Statistica 10.0 (StatSoft Inc., США). Переменные были проверены на нормальность распределения с помощью критерия Колмогорова-Смирнова. Данные представлены в виде медиан и интерквартильного размаха Me [Q1; Q3]. Сравнение групп осуществляли для качественных признаков - непараметрическим методом $X^{2}$ с поправкой Йейтса, а для количественных признаков U-тестом Манна-Уитни для двух независимых групп. Статистически значимым считали различие при значении $\mathrm{p}<0,05$.

\section{РЕЗУЛЬТАТЫ}

\section{Объекты (участники) исследования}

В исследование вошли 276 мужчин с СД2 (возраст 54,0 [49; 60] года, длительность СД2 - 6,0 [2,0; 10,0] года). Пациенты были разделены на 2 группы в соответствии с наличием или отсутствием симптомного гипогонадизма, 
Таблица 1. Характеристика групп пациентов в исследовании

\begin{tabular}{|c|c|c|c|}
\hline Показатель & $\begin{array}{c}\text { C гипогонадизмом } \\
(n=124)\end{array}$ & $\begin{array}{c}\text { Без гипогонадизма } \\
(n=152)\end{array}$ & $\mathbf{p}$ \\
\hline Возраст, лет & $54,0[50 ; 58]$ & $53,5[49,5 ; 58]$ & 0,661 \\
\hline Длительность СД2, лет & $5,0[2,0 ; 8,0]$ & $5,0[2,0 ; 10,0]$ & 0,414 \\
\hline \multicolumn{4}{|c|}{ Антропометрические показатели } \\
\hline Масса тела, кг & $103[92 ; 112]$ & $101,0[94 ; 107]$ & 0,143 \\
\hline ИМТ, кг/M² & $32,8[30,6 ; 36,1]$ & $32,7[30,6 ; 34,2]$ & 0,130 \\
\hline OT, см & $112[105 ; 122]$ & $112[106 ; 117]$ & 0,162 \\
\hline $\mathrm{Ob}, \mathrm{CM}$ & $110[104 ; 116]$ & $108[103 ; 114]$ & 0,128 \\
\hline \multicolumn{4}{|c|}{ Содержание гормонов в сыворотке крови } \\
\hline Общий тестостерон, нмоль/л & $10,1[7,7 ; 11,4]$ & $17,3[14,6 ; 20,4]$ & $<0,001$ \\
\hline Глобулин, связывающий половые гормоны, нмоль/л & $26,1[17,9 ; 37,6]$ & $31,0[23,7 ; 48,2]$ & 0,002 \\
\hline Свободный тестостерон, пмоль/мл & $212[146 ; 236]$ & $362[292 ; 448]$ & $<0,001$ \\
\hline ЛГ, мМЕ/мл & $3,8[2,3 ; 5,3]$ & $4,4[2,7 ; 5,9]$ & 0,072 \\
\hline
\end{tabular}

Примечания: СД2 — сахарный диабет 2 типа; ИМТ — индекс массы тела; ОТ — окружность талии; ОБ — окружность бедер; ЛГ — лютеинизирующий гормон.

диагностированного согласно критериям Российской ассоциации эндокринологов (2017) и Европейской ассоциации урологов (2014): 1-я - 124 мужчины, страдающие СД2 в сочетании с гипогонадизмом, 2-я - 152 эугонадных пациента с СД2. Группы были сопоставимы по возрасту, длительности СД2, массе тела, ИМТ, ОТ и ОБ (табл. 1).

Согласно принципу деления пациентов на группы, они значимо отличались по уровням общего и свободного Т ( $<<0,001)$, кроме того, были выявлены отличия в содержании ГСПГ, который был выше во 2-й группе по сравнению с 1-й $(p=0,002)$. Обращает на себя внимание несколько более высокий уровень ЛГ во 2-й группе $(p=0,07)$ относительно 1-й группы.

Нужно отметить, что наличие и тяжесть сердечно-сосудистых заболеваний не являлись критериями исключения из исследования, однако их структура и сопутствующая терапия требовали дополнительного анализа. Статистический анализ не выявил значимых различий в частоте ишемической болезни сердца и хронической сердечной недостаточности среди пациентов 1-й и 2-й групп ( $>>0,05)$. Так, ишемическая болезнь сердца была диагностирована у 36 человек (29\%) 1-й группы и 39 мужчин (25,7\%) 2-й группы, а хроническая сердечная недостаточность у $24(19,4 \%)$ и $26(17,1 \%)$ пациентов соответственно. Частота артериальной гипертензии у мужчин с гипогонадизмом была несколько выше, чем у эугонадных пациентов (95 (76,6\%) против 107 (70,4\%)), однако различие в уровнях систолического и диастолического артериального давления в группах не было статистически значимым, что позволяет проводить сравнительный анализ ЭД в группах. Сопутствующая терапия сердечно-сосудистых заболеваний была представлена гипотензивными и гиполипидемическими препаратами. Структура сопутствующей терапии была следующей: ингибиторы ангиотензинпревращающего фермента получали 36\%, $\beta$-адреноблокаторы и диуретики - по 30,2\%, антагонисты кальция $15,1 \%$, блокаторы рецепторов ангиотензина II - 12,6\%, агонисты имидазолиновых рецепторов - 2,9\%. Согласно медицинской документации, статины были назначены $82 \%$ больных, однако при сборе анамнеза было установлено, что регулярно их принимали лишь 65,8\% пациентов. При этом все препараты применялись в группах с сопоставимой частотой и в эквивалентных дозировках.

\section{Основные результаты исследования}

Нарушение сосудодвигательной функции эндотелия было выявлено у 32,4\% больных 2-й группы и у 55,3\% 1-й группы, что с высокой степенью достоверности $\left(x^{2}=6,1 ; p=0,01\right)$ позволяет утверждать, что гипогонадизм у мужчин с СД2 ассоциирован с развитием ЭД.

При проведении теста реактивной гиперемии значения исходного и максимального диаметров ПА между группами значимо не отличались (табл. 2). Однако было выявлено снижение ЭЗВД ПА на $29,8 \%(p<0,001)$ у пациентов 1-й группы по сравнению со 2-й. Статистический анализ показал, что время развития максимальной вазодилатации ПА было больше на 30 с у больных 1-й группы по сравнению со 2-й $(p<0,001)$. То есть

Таблица 2. Показатели эндотелий-зависимой вазодилатации

\begin{tabular}{lccc}
\hline \multicolumn{1}{c}{ Показатель } & $\begin{array}{c}\text { C гипогонадизмом Без гипогонадизма } \\
\text { (n=124) }\end{array}$ & (n=152) & p \\
\hline Исходный диаметр плечевой артерии при ЭЗВД, Мм & $4,8[4,3 ; 5,0]$ & $4,6[4,2 ; 5,0]$ & 0,215 \\
Максимальный диаметр плечевой артерии при ЭЗВД, мМ & $5,3[4,7 ; 5,6]$ & $5,2[4,9 ; 5,5]$ & 0,864 \\
ЭЗВД, \% & $9,4[6,9 ; 13,0]$ & $12,2[10,0 ; 16,7]$ & $<0,001$ \\
Время развития максимальной вазодилатации ПА, с & $120[90 ; 180]$ & $90[60 ; 90]$ & $<0,001$ \\
\hline
\end{tabular}

Примечания: ЭЗВД - эндотелий-зависимая вазодилатация; ПА - плечевая артерия. 
дефицит Т у мужчин с СД2 приводит не только к снижению артериальной вазореактивности почти на треть, но и к удлинению интервала времени развития ЭЗВД ПА.

Как видно из рис. 1, содержание NO в 1-й группе было снижено в 1,6 раза ( $p=0,001)$, что сопровождалось уменьшением концентрации еNOS3 в 1,5 раза $(p=0,038)$ по сравнению со 2-й группой. Поскольку известно, что NO является мощнейшим вазодилататором, столь значимый дефект его синтеза в условиях дефицита Т может являться основной причиной замедления и снижения ЭЗВД, показанных ранее. При этом содержание эндоте- лина в группах статистически значимо не различалось его уровень в 1-й группе составил 1,1 [0,7; 1,9] фмоль/мл, во 2 -й - 1,0 [0,6; 1,8] фмоль/мл $(p=0,446)$.

Сравнительный анализ содержания молекул адгезии у пациентов 1-й и 2-й групп представлен на рис. 2. Концентрация VCAM-1 была выше на 32,5\% (p<0,001), ICAM-1 на 43,5\% (p<0,001), p-селектина - на 19,3\% ( в 1-й группе по сравнению со 2-й ( $<<0,001)$. Аналогично, высокодостоверные данные были продемонстрированы в отношении еще одной молекулы адгезии - кадгерина, содержание которого было в 6 раз выше у мужчин,

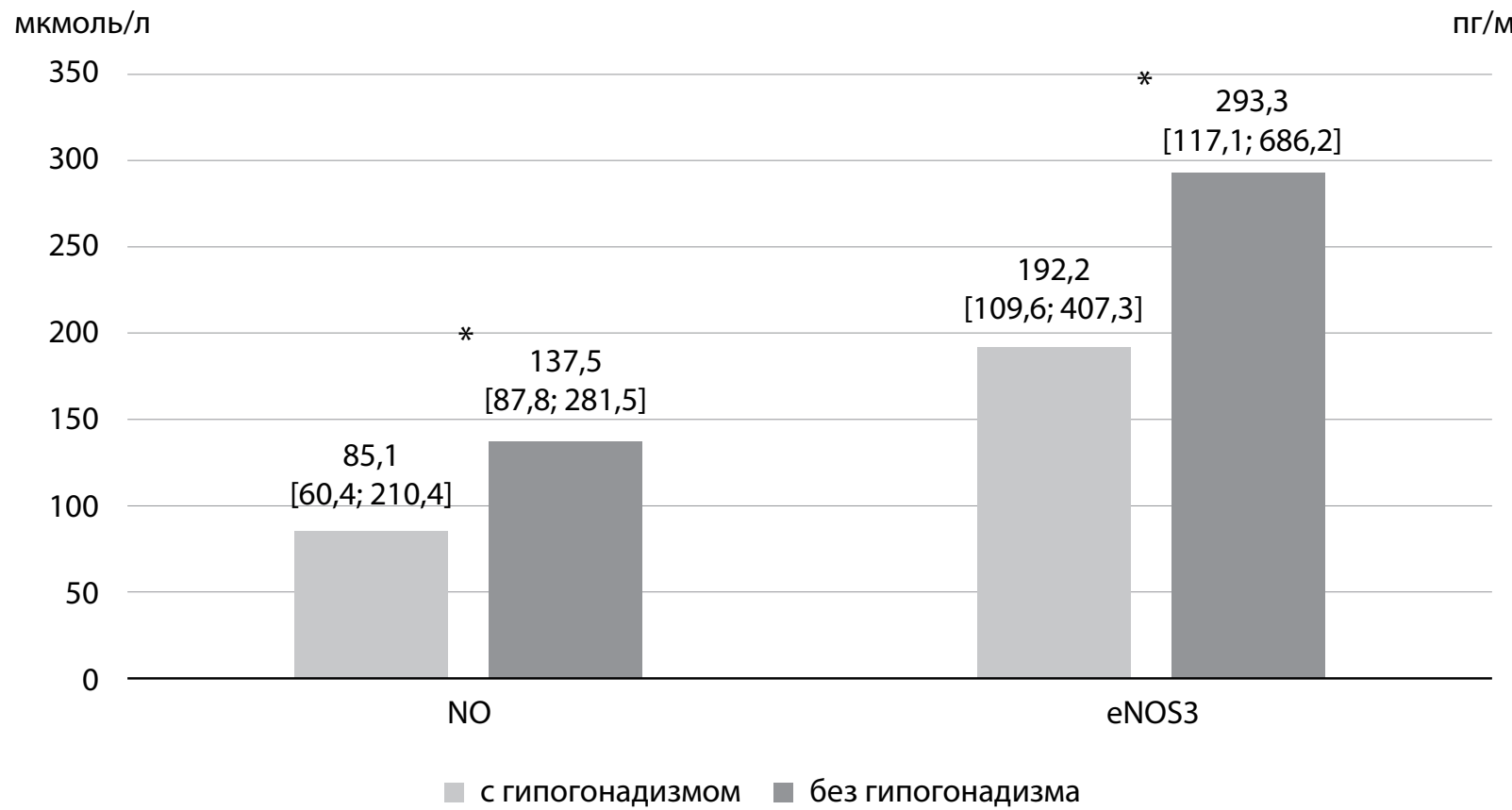

Рисунок 1. Сравнительный анализ содержания оксида азота и эндотелиальной синтазы 3 типа у мужчин с сахарным диабетом 2 типа в зависимости от наличия или отсутствия гипогонадизма. *- $\mathrm{p}<0,05$.

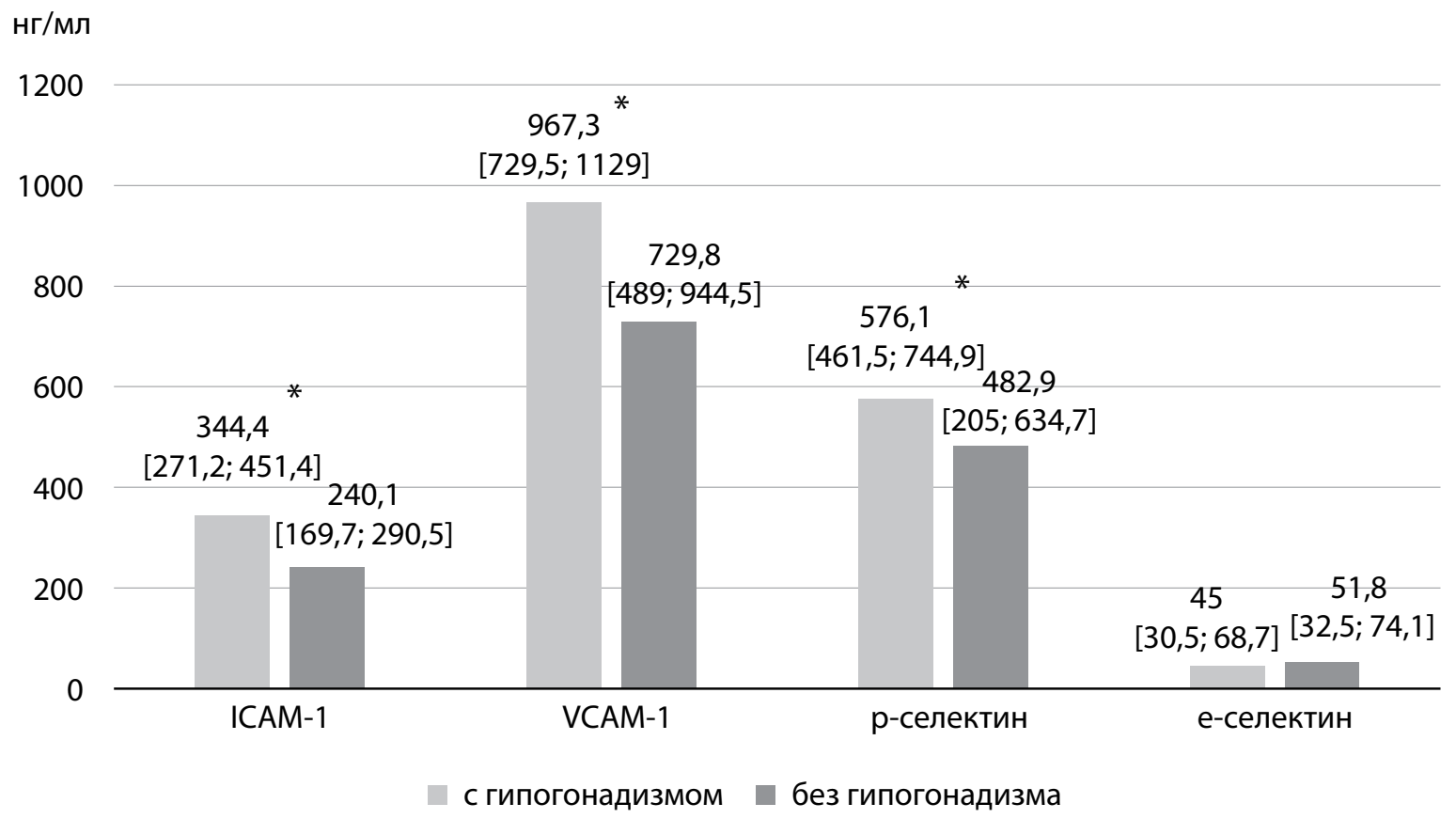

Рисунок 2. Сравнительный анализ содержания молекул адгезии у мужчин с сахарным диабетом 2 типа в зависимости от наличия или отсутствия гипогонадизма. *- ${ }^{*}<0,01$. 
Таблица 3. Показатели углеводного и липидного обменов

\begin{tabular}{lccc}
\hline \multicolumn{1}{c}{ Показатель } & $\begin{array}{c}\text { C гипогонадизмом } \\
\text { (n=124) }\end{array}$ & $\begin{array}{c}\text { Без гипогонадизма } \\
\text { (n=152) }\end{array}$ & p \\
\hline Глюкоза натощак, ммоль/л & $7,8[6,5 ; 10,7]$ & $7,9[6,4 ; 9,6]$ & 0,661 \\
$\mathrm{HbA}_{1 c^{\prime}} \%$ & $7,9[6,8 ; 10,3]$ & $7,7[6,6 ; 9,1]$ & 0,198 \\
ИРИ, мкMЕ/мл & $16,2[10,5 ; 30,2]$ & $12,7[8,4 ; 21,0]$ & 0,002 \\
Индекс НОМА-ІR, ед & $6,2[3,8 ; 11,0]$ & $4,6[2,8 ; 7,0]$ & $<0,001$ \\
ОХС, ммоль/л & $5,7[4,8 ; 6,6]$ & $5,1[4,6 ; 6,1]$ & 0,048 \\
ТГ, ммоль/л & $2,1[1,5 ; 2,9]$ & $1,6[1,3 ; 2,0]$ & $<0,001$ \\
ЛПВП, ммоль/л & $1,5[1,3 ; 1,6]$ & $1,4[1,3 ; 1,6]$ & 0,743 \\
ЛПОНП, ммоль/л & $1,1[0,8 ; 1,6]$ & $0,8[0,6 ; 0,9]$ & $<0,001$ \\
ЛПНП, ммоль/л & $3,3[2,5 ; 4,2]$ & $2,9[2,4 ; 3,6]$ & 0,020 \\
ИА, ед. & $2,9[2,6 ; 3,3]$ & $2,6[2,5 ; 3,0]$ & 0,007 \\
\hline
\end{tabular}

Примечания: $\mathrm{HbA}_{1 с}$ - гликированный гемоглобин; ИРИ - иммунореактивный инсулин; ОХС — общий холестерин; ТГ — триглицериды; ЛПВП — липопротеины высокой плотности; ЛПОНП — липопротеины очень низкой плотности; ЛПНП — липопротеины низкой плотности; ИА — индекс атерогенности.

имевших дефицит Т, по сравнению с эугонадными пациентами ( $<<0,001)$. Так, содержание кадгерина в 1-й группе составило 1,3 [0,1; 2,3] нг/мл, тогда как во 2-й группе его уровень достигал лишь 0,2 [0,1;0,4] нг/мл. Уровни е-селектина значимо между группами не отличались $(p=0,259)$.

\section{Дополнительные результаты исследования}

При анализе показателей углеводного обмена (табл. 3) было установлено, что группы значимо не отличались по уровню гликемии натощак и $\mathrm{HbA}_{1 c}$. В то же время выраженность гиперинсулинемии в 1-й группе была на 27,6\% выше ( $p=0,002)$, а индекс инсулинорезистентности HOMA-IR - в 1,3 раза выше $(p<0,001)$, чем во 2-й.

При изучении липидного спектра крови было выявлено статистически значимое увеличение уровней общего холестерина на $11,3 \%$ ( $\mathrm{p}=0,048)$, триглицеридов - на $28 \%$ $(p<0,001)$, липопротеидов низкой плотности - на 9,5\% $(p=0,02)$, а липопротеидов очень низкой плотности в 1,4 раза $(p<0,001)$ у больных с гипогонадизмом по сравнению с эугонадными пациентами. Уровни липопротеидов высокой плотности были сопоставимы в обеих группах $(p=0,743)$.Это сопровождалось увеличением индекса атерогенности на 9,5\% в 1-й группе по сравнению со 2-й ( $p=0,007)$.

Толщина КИМ сонных артерий в нашей выборке больных была статистически значимо $(p=0,03)$ больше на $10 \%$ у лиц с гипогонадизмом по сравнению с эугонадными пациентами (1 $[0,9 ; 1,2]$ мм против 0,9 [0,7; 1,1] мм).

Нежелательные явления

В ходе исследования нежелательные явления не были зарегистрированы.

\section{ОБСУЖДЕНИЕ}

\section{Резюме основного результата исследования}

На основании анализа результатов исследования, проведенного на 276 мужчинах с СД2, было установлено, что гипогонадизм сопряжен с увеличением частоты ЭД. Сочетание СД2 и гипогонадизма у мужчин ассоциировано с ухудшением сосудодвигательной функции эндотелия: снижением ЭЗВД наряду с увеличением времени развития максимальной вазодилатации ПА. Гипо- гонадизм приводит к нарушению секреторной функции эндотелия: увеличению концентраций молекул адгезии VCAM-1, ICAM-1, р-селектина, кадгерина и, напротив, уменьшению уровней NO, eNOS3.

\section{Обсуждение основного результата исследования}

Дисфункция эндотелия, определенная при помощи ультразвукового исследования, у мужчин с СД2 и гипогонадизмом встречалась в 1,7 раза чаще, что сопровождалось повышением толщины КИМ сонных артерий на $10 \%$ по сравнению с эугонадными пациентами. Толщина КИМ сонных артерий является важным прогностическим показателем атеросклеротического процесса, увеличение которого расценивается как неблагоприятный фактор прогрессии ЭД и отражает структурные изменения средней оболочки сонной артерии, что, по данным многочисленных исследований, ассоциируется с увеличением риска сердечно-сосудистых заболеваний. Известно, что увеличение данного показателя всего на 0,1 мм повышает риск развития инфаркта миокарда на 11\%, причем значение толщины КИМ более 0,9 мм как медиана показателя в группе гипогонадных пациентов свидетельствует о наличии доклинического атеросклероза [16]. То есть на фоне дефицита Т очевидно не только снижение сосудодвигательной функции эндотелия, но и структурные изменения средней оболочки сонной артерии, ассоциированные с увеличением риска сердечно-сосудистых заболеваний. Выявленные закономерности имеют особое значение для пациентов с СД2 и высоким кардиоваскулярным риском.

Традиционно при исследовании ЭЗВД изучаются ее пространственные характеристики, то есть прирост диаметра ПА в ходе теста реактивной гиперемии. В проведенном нами исследовании впервые было определено влияние дефицита Т не только на пространственные, но и на временные характеристики вазодилатации, то есть на то, как быстро развивается максимальная ЭЗВД ПА после декомпрессии. Детальное рассмотрение сосудодвигательной функции эндотелия привело к заключению, что гипогонадизм способствует снижению ЭЗВД на 29,8\%, но особую важность имеют данные о временных характеристиках вазодилатации. Впервые нами было установлено, что дефицит Т замедляет время развития 
эндотелий-зависимой вазодилатации. Особую важность имеет тот факт, что нарушение именно временных характеристик ЭЗВД происходит задолго до клинических проявлений сердечно-сосудистых заболеваний и ухудшения ее пространственных параметров $[15,17]$.

Объяснение этого феномена нужно искать в особенностях секреторной функции эндотелия, являющейся важнейшей составляющей его нормального функционирования. Для исследования нами были отобраны наиболее диагностически значимые молекулы, отражающие многочисленные функции эндотелия интимы сосудов: контроль сосудистого тонуса - эндотелин и NO; регуляция адгезивности сосудистой стенки - VCAM-1, ICAM-1, е- и р-селектины, кадгерин. Важнейшим и одним из наиболее изученных веществ, выделяемых эндотелием, является NO, который оказывает не только выраженное вазодилатирующее, но и вазопротекторное, антиагрегантное, противосвертывающее и противовоспалительное действия, в то же время поддерживает тонус сосудов и неадгезивность их внутренней поверхности $[4,18]$. Синтезируется NO ферментом NO-синтазой, которая представлена в эндотелии eNOS3. Активность фермента eNOS3, количество и скорость синтеза NO определяют благополучие эндотелия [18]. Проведенное нами исследование четко продемонстрировало выраженное снижение содержания как NO, так и eNOS3 у мужчин с гипогонадизмом, что свидетельствует об ослаблении механизмов эндотелиальной защиты и является патогенетической базой для нарушения вазодилятации. Физиологическим антагонистом NO в регуляции тонуса сосудов является эндотелин. Повышение его концентрации отмечено при ряде состояний, сопровождающихся ЭД, - инфаркте миокарда, легочной гипертензии, нарушениях ритма сердца. Однако в нашем исследовании содержание эндотелина в группах статистически значимо не различалось. Таким образом, можно утверждать, что дефицит Т приводит к значимому ослаблению вазодилататорных механизмов ЭД, существенно не влияя на вазоконстрикторные. Известно, что хроническая гипергликемия при СД2 снижает продукцию и биодоступность $\mathrm{NO}[2,3]$. Недавно было описано снижение концентрации NO наряду со снижением репаративных возможностей эндотелия у лиц с гипогонадизмом [19], то есть можно считать, что дефицит Т в значительной степени усугубляет нарушение продукции NO, вызываемое глюкозотоксичностью.

Одним из ранних признаков поражения эндотелия является повышение адгезивности сосудистой стенки, обусловленной гиперпродукцией сывороточных молекул адгезии: сосудистой (VCAM-1) и межклеточной (ICAM -1), е- и р- селектинов, кадгерина. Усиление их экспрессии на поверхности эндотелиоцитов на ранних стадиях атерогенеза способствует адгезии лейкоцитов и субэндотелиальному проникновению липопротеидов, формирующих атеросклеротическую бляшку [4, 20]. Нами было установлено, что у мужчин с гипогонадизмом повышены концентрации VCAM-1 на 32,5\%, ICAM-1 на 43,5\%, р-селектина - на 19,3\%, а кадгерина — в 6 раз по сравнению с пациентами с нормотестостеронемией. Экспрессия данных молекул адгезии, не синтезирующихся в нормальных условиях, является отражением активации эндотелия, возникающей на фоне хронической гипергликемии и глюкозотоксичности и усугубляемой дефицитом Т. Повышение адгезивности эндотелия способствует атерогенезу и прогрессии микро- и макросо- судистых осложнений диабета, что особенно актуально у мужчин с СД2 в сочетании с гипогонадизмом.

Таким образом, можно утверждать, что дефицит Т приводит к ЭД за счет ослабления синтеза вазодилататоров и усиления адгезивности сосудистой стенки.

\section{Ограничения исследования}

Ограничением исследования является отсутствие расчета объема выборки. Все пациенты в исследовании имели диагноз СД2, что не позволяет экстраполировать полученные результаты на популяцию мужчин с дефицитом Т без нарушений углеводного обмена и требует дальнейшего проведения исследований.

\section{Направления дальнейших исследований}

В дальнейшем вызывают интерес изучение влияния заместительной терапии Т на функцию эндотелия у мужчин с СД2 и определение роли чувствительности андрогеновых рецепторов в реализации эффектов Т на эндотелий.

\section{ЗАКЛЮЧЕНИЕ}

На сегодняшний день известно, что смертность мужчин с СД2 в сочетании с гипогонадизмом от кардиоваскулярных заболеваний вдвое выше, чем у эугонадных пациентов, однако механизмы действия Т на сердечно-сосудистую систему до конца не изучены. Результаты проведенного нами исследования выявили нарушение функции эндотелия у мужчин с гипогонадизмом по сравнению с эугонадными пациентами, что проявляется в ослаблении ЭЗВД и замедлении ее развития, а также нарушении секреторной активности эндотелия - снижении синтеза NO и активации экспрессии молекул адгезии VCAM-1, ICAM-1, p-селектина и кадгерина. Нарушение сосудодвигательной функции эндотелия наряду с нарастанием адгезивности сосудистой стенки может являться универсальным патогенетическим механизмом развития сердечно-сосудистых заболеваний при гипогонадизме у мужчин с СД2.

У больных СД ИБС часто протекает в бесссимптомной форме. В задачи исследования не входрил поиск ССЗ при помощи дополнительных инструментальных исследований. Информацию о наличии/отсутствии СС3, сопутствующей терапии получали из доступной медицинской документации и со слов пациента.

\section{ДОПОЛНИТЕЛЬНАЯ ИНФОРМАЦИЯ}

Источник финансирования. Работа выполнена при поддержке Российского научного фонда, грант № 14-25-00052.

Конфликт интересов. Авторы статьи заявляют об отсутствии финансовой заинтересованности и других потенциальных конфликтов интересов, связанных с публикацией настоящей статьи.

Участие авторов. Хрипун И.А. - концепция и дизайн исследования, сбор и анализ результатов, написание текста; Воробьев С.В. дизайн исследования, коррекция текста. Все авторы одобрили финальную версию статьи перед публикацией, выразили согласие нести ответственность за все аспекты работы, подразумевающую надлежащее изучение и решение вопросов, связанных с точностью или добросовестностью любой части работы.

Благодарности. Авторы выражают признательность всем членам научного коллектива, осуществлявшим работу по реализации гранта Российского научного фонда № 14-25-00052. 


\section{СПИСОК ЛИТЕРАТУРЫ | REFERENCES}

1. IDF diabetes atlas, 9th edition 2019. International Diabetes Federation. - IDF, 2020. Available from: https://www.diabetesatlas.org/en/ (12.06.2020).

2. Аметов А.С. Сахарный диабет 2 типа. Проблемы и решения. 3-е изд., перераб. и доп. - М.: ГЭОТАР-Медиа; 2015. - Т. 1. — 352 c. [Ametov A.S. Saharnyj diabet 2 tipa. Problemy i reshenija. 3-e izd., pererab. i dop. M.: GEOTAR-Media; 2015. 352 p. (In Russ.)].

3. Takeda Y, Matoba K, Sekiguchi K, et al. Endothelial Dysfunction in Diabetes. Biomedicines. 2020;8(7):182. doi: https://doi.org/10.3390/biomedicines8070182.

4. Godo S, Shimokawa H. Endothelial Functions. Arterioscler. Thromb. Vasc. Biol. 2017;37(9):e108-e114. doi: https://doi.org/10.1161/ATVBAHA.117.309813

5. Хрипун И.А., Воробьев С.В., Моргунов М.Н., Коган М.И. Функция эндотелия у мужчин с сахарным диабетом 2 типа, не имеющих клинических признаков сердечно-сосудистых заболеваний // Сахарный диабет. - 2016. - Т. 19. - №5. - С. 383-387. [Khripun IA, Vorobyev SV, Morgunov MN, Kogan MI. Endothelial function in men with type 2 diabetes without clinical signs of cardiovascular disease. Diabetes mellitus. 2016;19(5):383-387. (In Russ.)]. doi: https://doi.org/10.14341/DM8017

6. Triggle CR, Ding H, Marei I, Anderson TJ, Hollenberg MD. Why the endothelium? The endothelium as a target to reduce diabetes-associated vascular disease. Can J Physiol Pharmacol. 2020;98(7):415-430. doi: https://doi.org/10.1139/cjpp-2019-0677

7. Zhang J, Li X, Cai Z, et al. Association between testosterone with type 2 diabetes in adult males, a meta-analysis and trial sequential analysis. Aging Male. 2020;23(5):607-618. doi: https://doi.org/10.1080/13685538.2018.1557139

8. Rastrelli G, Filippi S, Sforza A, et al. Metabolic Syndrome in Male Hypogonadism. In: Frontiers of Hormone Research. 2018:131-155. doi: https://doi.org/10.1159/000485999

9. Jones TH, Kelly DM. Randomized controlled trials-mechanistic studies of testosterone and the cardiovascular system. Asian J Androl. 2018. doi: https://doi.org/10.4103/aja.aja-6-18

10. Мельниченко Г.А., Шестакова М.В., Роживанов Р.В. Распространенность синдрома гипогонадизма у мужчин с сахарным диабетом типа 2 в условиях рутинной клинической практики // Сахарный диабет. — 2019. - Т. 22. — №2. C. 127-130. [Melnichenko GA, Shestakova MV, Rozhivanov RV. The prevalence of hypogonadism in men with diabetes mellitus (DM) type 2 in clinical practice. Diabetes Mellitus. 2019;22(2):127-130. (In Russ.)]. doi: https://doi.org/10.14341/DM9944

11. Blaya R, Blaya P, Rhoden L, et al. Low Testosterone Levels and Metabolic Syndrome in Aging Male. Curr Pharm Des. 2017;23(30):4470-4474. doi: https://doi.org/10.2174/1381612823666170503150955
12. Lucas-Herald AK, Alves-Lopes R, Montezano AC, et al. Genomic and non-genomic effects of androgens in the cardiovascular system: clinical implications. Clin. Sci. (Lond). 2017;131(13):1405-1418. doi: https://doi.org/10.1042/CS20170090

13. Chistiakov DA, Myasoedova VA, Melnichenko AA, et al. Role of androgens in cardiovascular pathology. Vasc. Health Risk Manag. 2018;14:283-290.

14. Torres-Estay V, Carreño DV, Fuenzalida P, et al. Androgens modulate male-derived endothelial cell homeostasis using androgen receptordependent and receptor-independent mechanisms. Angiogenesis. 2017;20(1):25-38. doi: https://doi.org/10.1007/s10456-016-9525-6

15. Хрипун И.А., Воробьев С.В., Коган М.И. Взаимосвязь полиморфизма гена рецептора андрогенов и функции эндотелия у мужчин с сахарным диабетом 2 типа // Сахарный диабет. 2015. - № 4. - C. 28-33. [Khripun IA, Vorobiev SV, Kogan MI. Association of the polymorphism in the androgen receptor gene and endothelial function in men with type 2 diabetes. Diabetes mellitus. 2015;4:28-33. (In Russ.)]. doi: https://doi.org/10.14341/DM7622

16. Nambi V, Chambless L, He M, et al. Common carotid artery intima-media thickness is as good as carotid intima-media thickness of all carotid artery segments in improving prediction of coronary heart disease risk in the Atherosclerosis Risk in Communities (ARIC) study. Eur. Heart J. 2012;33(2):183-190. doi: https://doi.org/10.1093/eurheartj/ehr192

17. Хрипун И.А., Моргунов М.Н., Воробьев С.В., и др. Эндотелиальная дисфункция и сахарный диабет 2 типа: новые маркеры ранней диагностики // Кардиоваскулярная терапия и профилактика. - 2016. - Т. 15. - № 5. - С. 59-63. [Khripun IA, Morgunov MN, Vorobyov SV, et al. Endothelial dysfuncton and 2 type diabetes: novel markers for earlier diagnostics. Cardiovascular Therapy and Prevention. 2016;15(5):59-63. (In Russ.)]. doi: https://doi.org/10.15829/1728-8800-2016-5-59-63

18. Farah C, Michel LYM, Balligand JL. Nitric oxide signalling in cardiovascular health and disease. Nat Rev Cardiol. 2018;15(5):292-316. doi: https://doi.org/10.1038/nrcardio.2017.224

19. Hotta Y, Kataoka T, Kimura K. Testosterone Deficiency and Endothelial Dysfunction: Nitric Oxide, Asymmetric Dimethylarginine, and Endothelial Progenitor Cells. Sex Med Rev. 2019;7(4):661-668. doi: https://doi.org/10.1016/j.sxmr.2019.02.005

20. Степанова Т.В., Иванов А.Н., Терешкина Н.Е., и др. Маркеры эндотелиальной дисфункции: патогенетическая роль и диагностическое значение (обзор литературы) // Клиническая и лабораторная диагностика. - 2019. - Т. 64. - №1. C. 34-41. [Stepanova TV, Ivanov AN, Tereshkina NE, et al. Markery jendotelial'noj disfunkcii: patogeneticheskaja rol'i diagnosticheskoe znachenie (obzor literatury) / Klinicheskaja i laboratornaja diagnostika. 2019;64(1):34-41 (In Russ.)].

\section{ИНФОРМАЦИЯ ОБ АВТОРАХ [AUTHORS INFO]}

*Хрипун Ирина Алексеевна, д.м.н., доцент [Irina I. Khripun, MD, PhD, assistant professor]; адрес: Россия, 344022, г. Ростов-на-Дону, пер. Нахичеванский, д. 29 [address: 29, Nakhichevanski lane, 344022 Rostov on Don, Russian Federation]; ORCID: https://orcid.org/0000-0003-0284-295X; eLibrary SPIN: 8630-4828; email: khripun.irina@gmail.com

Воробьев Сергей Владиславович, д.м.н., профессор [Sergey V. Vorobyev, MD, PhD, Professor]; ORCID: https://orcid.org/0000-0001-7884-2433; eLibrary SPIN: 9773-6100; e-mail: endocrinrostov@mail.ru

\section{ЦИТИРОВАТЬ:}

Хрипун И.А., Воробьев С.В. Состояние функции эндотелия у мужчин с гипогонадизмом // Cахарный диабет. - 2021. T. 24. — №5. - C. 440-447. doi: https://doi.org/10.14341/DM12780

\section{TO CITE THIS ARTICLE:}

Khripun IA, Vorobyev SB. Endothelial function status in hypogonadal men. Diabetes Mellitus. 2021;24(5):440-447. doi: https://doi.org/10.14341/DM12780 